\title{
QUENCHING OF $\mathrm{O}^{+}\left({ }^{2} \mathrm{D}\right)$ BY ELECTRONS IN THE THERMOSPHERE
}

\author{
MARSHA R. TORR*, D. G. TORR* and P. RICHARDS \\ Space Physics Research Laboratory, The University of Michigan, Ann Arbor, MI 48109, U.S.A.
}

(Received in final form 20 November, 1979)

\begin{abstract}
A major loss process for the metastable species. $\mathrm{O}^{+}\left({ }^{2} \mathrm{D}\right)$, in the thermosphere is quenching by electrons

$$
\mathrm{O}^{+}\left({ }^{2} \mathrm{D}\right)+e \rightarrow \mathrm{O}^{+}\left({ }^{4} \mathrm{~S}\right)+e .
$$

To date no laboratory measurement exists for the rate coefficient of this reaction. Thermospheric models involving this process have thus depended on a theoretically calculated value for the rate coefficient and its variation with electron temperature. Earlier studies of the $\mathrm{O}^{+}\left({ }^{2} \mathrm{D}\right)$ ion based on the Atmosphere Explorer data gathered near solar minimum, could not quantify this process. However, Atmosphere Explorer measurements made during 1978 exhibit electron densities that are significantly enhanced over those occurring in 1974, due to the large increases that have occurred in the solar extreme ultraviolet flux. Under such conditions, for altitudes $\geqslant 280 \mathrm{~km}$, the electron quenching process becomes the major loss mechanism for $\mathrm{O}^{+}\left({ }^{2} \mathrm{D}\right)$, and the chemistry of the $\mathrm{N}_{2}{ }^{+}$ion, from which the $\mathrm{O}^{+}\left({ }^{2} \mathrm{D}\right)$ density is deduced, simplifies to well determined processes. We are thus able to use the in situ satellite measurements made during 1978 to derive the electron quenching rate coefficient. The results confirm the absolute magnitude of the theoretical calculation of the rate coefficient, given by the analytical expression $\mathrm{k}\left(T_{e}\right)=7.8 \times 10^{-8}\left(T_{e} / 300\right)^{-0.5} \mathrm{~cm}^{3} \mathrm{~s}^{-1}$. There is an indication of a stronger temperature dependence, but the agreement is within the error of measurement.
\end{abstract}

\section{INTRODUCTION}

Chemical reactions involving quenching of metastable species by electrons play an important role in the energy balance of the thermosphere. One such metastable species is $\mathrm{O}^{+}\left({ }^{2} \mathrm{P}\right)$ for which electron quenching is the major loss process in the topside ionosphere. As $\mathrm{O}^{+}\left({ }^{2} \mathrm{D}\right)$ is not measured directly by the Atmosphere Explorer satellites, we have studied this constituent largely via its effect on the $\mathrm{N}_{2}^{+}$photochemistry (Orsini et al, 1977; Torr and Orsini, 1978; Torr, 1979; Torr and Torr, $1980) . \mathrm{O}^{+}\left({ }^{2} \mathrm{D}\right)$ is in photochemical equilibrium to altitudes greater than $400 \mathrm{~km}$. At the altitudes considered here, $\geq 280 \mathrm{~km}$, the significant sources in the $\mathrm{O}^{+}\left({ }^{2} \mathrm{D}\right)$ chemistry are as follows [see Torr et al. (1980) and the references cited therein]:

$$
\begin{gathered}
\mathrm{O}+\mathrm{h} \nu \stackrel{\mathrm{q}_{1}}{\longrightarrow} \mathrm{O}^{+}\left({ }^{2} \mathrm{D}\right)+e \\
\mathrm{O}^{+}\left({ }^{2} \mathrm{P}\right) \stackrel{\beta}{\rightarrow} \mathrm{O}^{+}\left({ }^{2} \mathrm{D}\right)
\end{gathered}
$$

In equation (1), $q_{1}$ is an effective ionization frequency which includes both photoionization and photoelectron ionization. In order to obtain the component of $q_{1}$ due to photons we have used the

\footnotetext{
* Also affiliated with National Institute for Telecommunications Research of the S.A. C.S.I.R., Johannesburg, South Africa.
}

calculated ionization frequencies as a function of increasing solar activity determined by Torr et al (1979). We have interpolated to the days on which the measurements used in this study were made by fitting an F10.7 dependence to the ionization frequencies calculated for specific days throughout the increasing phase of solar cycle 21. Atmospheric attenuation has been taken into account. We have assumed that the photoelectron contribution is $15 \%$ of the photoionization frequency (Torr and Torr, 1980). The photoelectron contribution is, however, uncertain and could be as high as $45 \%$ (Oppenheimer et al., 1977) at these altitudes. We discuss below the effect of this uncertainty on our results.

It is reasonable to assume that at the altitudes considered in this study $(280-380 \mathrm{~km})$, all of the $\mathrm{O}^{+}\left({ }^{2} \mathrm{P}\right)$ that is produced is deactivated to $\mathrm{O}^{+}\left({ }^{2} \mathrm{D}\right)$, either by cascading or by quenching. This source is represented by equation (2). We calculate the $\mathrm{O}^{+}\left({ }^{2} \mathrm{P}\right)$ concentration in a similar way, from photoionization and photoelectron ionization of $\mathrm{O}$. The chemistry is well established (Rusch et al., 1977).

Loss processes for $\mathrm{O}^{+}\left({ }^{2} \mathrm{D}\right)$ arc:

$$
\begin{aligned}
& \mathrm{O}^{+}\left({ }^{2} \mathrm{D}\right)+\mathrm{N}_{2} \stackrel{\mathrm{k}_{1}}{\longrightarrow} \mathrm{N}_{2}^{+}+\mathrm{O} \\
& \mathrm{k}_{1}=(7 \pm 3) \times 10^{-11} \mathrm{~cm}^{3} \mathrm{~s}^{-1}
\end{aligned}
$$

(Torr and Torr, 1979b; Torr et al., 1980) 


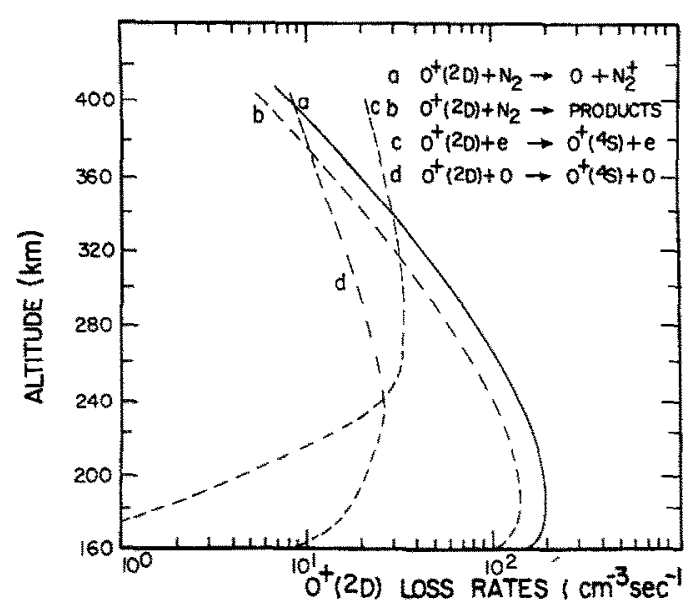

FIG. 1. MODELLED $\mathrm{O}^{+}\left({ }^{2} \mathrm{D}\right)$ LOSS RATES For MidLATTTUDE, DAYTIME CONDTIONS FOR F10.7 $=160$.

$$
\begin{gathered}
\mathrm{O}^{+}\left({ }^{2} \mathrm{D}\right)+\mathrm{N}_{2} \stackrel{\mathrm{k}_{2}}{\longrightarrow} \text { or }\left\{\begin{array}{l}
\mathrm{O}^{+}\left({ }^{4} \mathrm{~S}\right)+\mathrm{N}_{2} \\
\mathrm{NO}^{+}+\mathrm{N}
\end{array}\right. \\
\mathrm{k}_{2}=\left(3 \pm \frac{7}{2}\right) \times 10^{-11} \mathrm{~cm}^{3} \mathrm{~s}^{-1}
\end{gathered}
$$

(Torr and Torr, 1979b)

$$
\begin{gathered}
\mathrm{O}^{+}\left({ }^{2} \mathrm{D}\right)+e \stackrel{\mathrm{k}_{3}}{\longrightarrow} \mathrm{O}^{+}\left({ }^{4} \mathrm{~S}\right)+\mathrm{e} \quad \text { (see text) } \\
\mathrm{O}^{+}\left({ }^{2} \mathrm{D}\right)+\mathrm{O} \stackrel{k_{4}}{\longrightarrow} \mathrm{O}^{+}\left({ }^{4} \mathrm{~S}\right)+\mathrm{O} \\
\mathrm{k}_{4} \leq 1 \times 10^{-11} \mathrm{~cm}^{3} \mathrm{~s}^{-1}
\end{gathered}
$$

(Orsini et al., 1977; Torr and Torr, 1979b)

For the purposes of this study, we set $k_{4}$ to zero. At altitudes above $280 \mathrm{~km}$ charge exchange of $\mathrm{O}^{+}\left({ }^{2} \mathrm{D}\right)$ with $\mathrm{O}_{2}$ can be neglected. We can thus write

$$
\begin{array}{r}
{\left[\mathrm{O}^{+}\left({ }^{2} \mathrm{D}\right)\right]=\left\{\mathrm{q}_{1}[\mathrm{O}]+\beta\left[\mathrm{O}^{+}\left({ }^{2} \mathrm{P}\right)\right]\right\} /\left(\mathrm{k}_{1}\left[\mathrm{~N}_{2}\right]+\mathrm{k}_{2}\left[\mathrm{~N}_{2}\right]\right.} \\
+\mathrm{k}_{3}\left[\mathrm{~N}_{\mathrm{e}}\right]
\end{array}
$$

Under circumstances where reaction (5) is the major loss mechanism for $\mathrm{O}^{+}\left({ }^{2} \mathrm{D}\right)$, we can rearrange equation (7) to solve for $k_{3}$ as follows:

$$
\begin{array}{r}
\mathrm{k}_{3}\left(\mathrm{~T}_{\mathrm{e}}\right)=\frac{1}{\left[\mathrm{~N}_{e}\right]}\left[\left\{\mathrm{q}_{1}[\mathrm{O}]+\beta\left[\mathrm{O}^{+}\left({ }^{2} \mathrm{P}\right)\right] /\left[\mathrm{O}^{+}\left({ }^{2} \mathrm{D}\right)\right]\right.\right. \\
\left.-\left(\mathrm{k}_{1}+\mathrm{k}_{2}\right)\left[\mathrm{N}_{2}\right]\right]
\end{array}
$$

Electron quenching is an important loss mechanism at altitudes greater than $280 \mathrm{~km}$, for conditions corresponding to $\mathrm{F} 10.7$ around 160 ; i.e., conditions representative of 1978 . This is illustrated in Fig. 1 which shows theoretical loss rates for this period.

As $\mathrm{O}^{+}\left({ }^{2} \mathrm{D}\right)$ concentrations are not measured directly by the satellite borne instrumentation, this species must be indirectly determined. Using the AE database of measured parameters, this determi- nation can best be made through the $\mathrm{N}_{2}{ }^{+}$ chemistry.

It has been shown in earlier work (see Torr et al., 1980 and references cited therein) that the $\mathrm{N}_{2}{ }^{+}$ concentration is given by:

$$
\left[\mathrm{N}_{2}^{+}\right]=\left\{\mathrm{k}_{1}\left[\mathrm{O}^{+}\left({ }^{2} \mathrm{D}\right)\right]\left[\mathrm{N}_{2}\right]+q_{2}\left[\mathrm{~N}_{2}\right]\right\} /\left\{\alpha_{1}\left[\mathrm{~N}_{e}\right]+\mathrm{k}_{s}[\mathrm{O}]\right\}
$$

where $q_{2}$ is an effective ionization frequency which includes both photon and electron contributions, the latter at $30 \%$ of the photoionization rate. We determine $q_{2}$ as was discussed above for $\mathrm{O}^{+}\left({ }^{2} \mathrm{D}\right)$.

The rate coefficients $k_{1}, k_{5}$ and $\alpha_{1}$ are well determined. By appropriate selection of data, the determination of $\mathrm{k}_{5}$ was made independence of any other rate coefficient. The aeronomic determination of $\alpha_{1}$ depended only weakly on $k_{5}$, and $k_{1}$ depended on $\alpha_{1}$ and $k_{5}$. In order to clarify how these determinations were achieved, we briefly review this earlier work here. For high solar activity, such as prevailed during 1978, the major source of $\mathrm{N}_{2}^{+}$ is photoionization, and thus the determination of $\mathrm{N}_{2}{ }^{+}$is not influenced by uncertainties in the $\mathrm{O}^{+}\left({ }^{2} \mathrm{D}\right)$ chemistry. This is also true at altitudes $5220 \mathrm{~km}$ at solar minimum. Using satellite data obtained below $200 \mathrm{~km}$ near solar minimum, Torr et al. (1977) were thus able to determine $k_{5}$ under conditions where photoionization is the major source and the ion-atom interchange with $\mathrm{O}$ is the major sink. Their result agreed with the laboratory measurements by McFarland et al. (1974).

Using measurements made during 1978, Torr and Torr (1979c) were able to determine $\alpha_{1}$, for the case where photoionization is the major source, and under conditions where both $\mathrm{N}_{2}^{+}$loss mechanisms are important. Since the solar minimum data had established $k_{5}$, a reliable determination of $\alpha_{1}$ was possible. The Torr and Torr (1979c) result for $\alpha_{1}$ confirmed the laboratory measurements by Mehr and Biondi (1969) and Mul and McGowan (1979). Torr et al. (1980) then used these results to refine an earlier determination of $\mathrm{k}_{1}$.

On the basis of these studies, we believe that the $\mathrm{N}_{2}{ }^{+}$concentration given by equation (9) is more reliable than $\mathrm{O}^{+}\left({ }^{2} \mathrm{D}\right)$ concentration given by equation (7). Using the satellite measurements of the densities that appear in (9) and the rate coefficients already discussed, we can rearrange equation (9) to obtain $\mathrm{O}^{+}\left({ }^{2} \mathrm{D}\right)$ concentrations in terms of $\left[\mathrm{N}_{2}{ }^{+}\right]$,

$$
\begin{aligned}
{\left[\mathrm{O}^{+}\left({ }^{2} \mathrm{D}\right)\right]=} & 1 /\left\{\mathrm{k}_{1}\left[\mathrm{~N}_{2}\right]\right\} \\
& \times\left\{\left[\mathrm{N}_{2}{ }^{+}\right]\left(\alpha_{1}\left[\mathrm{~N}_{e}\right]+\mathrm{k}_{\mathrm{s}}[\mathrm{O}]\right)-q_{2}\left[\mathrm{~N}_{2}\right]\right\}
\end{aligned}
$$

These $\mathrm{O}^{+}\left({ }^{2} \mathrm{D}\right)$ concentrations are then used in equation (8) to solve for $k_{3}$. Because electron quenching is the major loss process under the conditions 


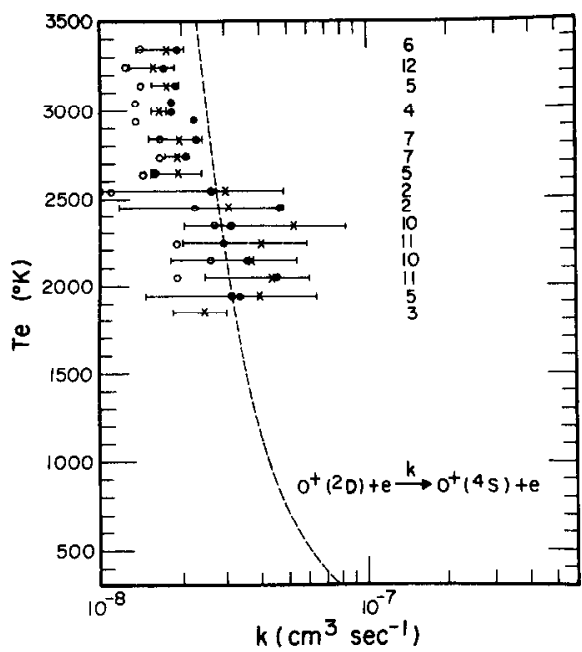

Fig. 2. Determination of RATE COefFicient FOR $\mathrm{O}^{+}\left({ }^{2} \mathrm{D}\right)+e \rightarrow \mathrm{O}^{+}(4 \mathrm{~S})+e$.

The (O) are for $k_{2}=1 \times 10^{-10} \mathrm{~cm}^{3} \mathrm{~s}^{-1},(\times)$ for $k_{2}=$ $1 \times 10^{-11} \mathrm{~cm}^{3} \mathrm{~s}^{-1}$, (O) for $\mathrm{k}_{2}=1 \times 10^{-10} \mathrm{~cm}^{3} \mathrm{~s}^{-1}$ and the higher efficiency for photoelectron ionization as discussed in the text. The bars indicate the standard deviation of the averages calculated in each $100^{\circ} \mathrm{K} T_{e}$ interval (shown on the central set of results but typical of the others). The sample size for each bin is shown to the right of the figure. The dashed line is the theoretical result of Henry et al. (1969).

we are studying, the solution is not sensitive to uncertainties in $\mathrm{k}_{2}$.

\section{RESULTS}

The ion concentrations used in this study were measured by the Bennett ion mass spectrometer (Brinton et al., 1973). The electron temperatures and concentrations were measured by the cylindrical electrostatic probe (Brace et al., 1973). The ion temperatures were measured by the retarding potential analyzer (Hanson et al., 1973), and the concentrations of the neutral species by the closed source mass spectrometer (Spencer et al., 1973). When neutral concentrations were not measured by the satellite, we have used $[\mathrm{O}]$ and $\left[\mathrm{N}_{2}\right]$ from the MSIS model (Hedin et al., 1977).

The results of the calculation of $k_{3}$ are shown in Fig. 2, in which we also demonstrate the sensitivity of the solution to uncertainties in key rate coefficients. These are as follows. The open circles show the results using $\mathrm{k}_{1}=5 \times 10^{-11} \mathrm{~cm}^{3} \mathrm{~s}^{-1}$ and $\mathrm{k}_{2}=$ $1 \times 10^{-10} \mathrm{~cm}^{3} \mathrm{~s}^{-1}$. The latter is the upper limit to this rate coefficient as determined by Torr and Torr $(1979 \mathrm{c})$. These values together with the other rate coefficients already quoted yield the best agreement between calculated and observed $\mathrm{N}_{2}^{+}$(Torr et al., 1980). The crosses show the values obtained for $k_{3}$ using the same chemical scheme as before, but with $\mathrm{k}_{2}=1 \times 10^{-11} \mathrm{~cm}^{3} \mathrm{~s}^{-1}$. This is the lower limit to this rate coefficient established by Torr and Torr $(1979 \mathrm{c})$, and thus these two sets of results bracket the uncertainty in this parameter. However, $\mathrm{k}_{2}=$ $1 \times 10^{-11} \mathrm{~cm}^{3} \mathrm{~s}^{-1}$ did not produce as good an agreement between measured and calculated $\mathrm{N}_{2}{ }^{+}$(Torr et al., 1980) as $\mathrm{k}_{2}=1 \times 10^{-10} \mathrm{~cm}^{3} \mathrm{~s}^{-1}$. The dots show the results obtained for $\mathrm{k}_{3}$ using a higher ionization rate by photoelectrons, namely $45 \%$ of the photoionization rate, as discussed above. This result is in better agreement with the theoretical determination of $\mathrm{k}_{3}$ (Henry et al., 1969) given by

$$
\mathrm{k}_{3}\left(\mathrm{~T}_{e}\right)=7.8 \times 10^{-8}\left(\mathrm{~T}_{e} / 300\right)^{-0.5} \mathrm{~cm}^{3} \mathrm{~s}^{-1}
$$

and shown as the dashed curve in Fig. 2 but no weight can be placed on it from this study. The impact on the $\mathrm{N}_{2}{ }^{+}$chemistry of using the high photoelectron efficiency is less than $10 \%$. In Fig. 2 the points represent the average value of $k_{3}$ in a $100^{\circ} \mathrm{K}$ electron temperature interval. The bars indicate the standard deviation of the average; standard deviations are shown for the central set of results, but are typical of the other two sets.

\section{CONCLUSIONS}

Using satellite measurements of the relevant ionospheric parameters, we have determined the rate coefficient for quenching of $\mathrm{O}^{+}\left({ }^{2} \mathrm{D}\right)$ by electrons as a function of temperature. The results agree with the theoretically determined rate coefficient to within statistical uncertainties. This study therefore provides confirmation of the absolute magnitude of the rate coefficient given by the theoretical calculation at these temperatures. The results do indicate, however, a somewhat steeper dependence on electron temperature than predicted by theory. As this indication is within the uncertainty on the measurements we cannot place any strong reliance on it at this time. We therefore recommend use of equation (11) until further studies show a need for different parameterization.

Acknowledgements-We thank I. H. Brace, H. C. Brinton, N. W. Spencer and W. B. Hanson for providing the data used in this study. This work was supported by a NASA grant NAS5-24331 to the University of Michigan.

\section{REFERENCES}

Brace, L. H., Theis, R. F. and Dalgarno, A. (1973). Radio Sci., 8, 341.

Brinton, H. C., Scott, L. R., Pharo, M. W. III, and Coulson, J. T. C. (1973). Radio Sci., 8, 323. 
Hanson, W. B., Zuccaro, D. R., Lippincott, C. R. and Sanatani, S. (1973). Radio Sci., 8, 333.

Hedin, A. E., Salah, J. E., Evans, J. V., Reber, C. A., Newton, G. P., Spencer, N. W., Kayser, D. C., Alcayde, D., Bauer, P., Cogger, L. and McClure, J. P. (1977). J. Geophys. Res., 82, 2139.

Henry, R. J. W., Burke, P. G. and Sinfailam, A. L. (1969). Phys. Rev., 178, 218.

McFarland, M., Albritton, D. L., Fehsenfeld, F. C., Ferguson, E. E. and Schmeltekopf, A. L. (1974). J. Geophys. Res., 79, 2925.

Mehr, F. J. and Biondi, M. A. (1969). Phys. Rev., 181, 264.

Mul, P. M. and McGowan, J. W. (1979). J. Phys. B., (in press).

Oppenheimer, M., Constantinides, E. R., Kirby-Docken, K., Brinton, H. C. and Hoffman, J. H. (1977). J. Geophys. Res., 82, 5485.

Orsini, N., Torr, D. G., Torr, M. R., Brinton, H. C., Bracc, L. H., Nier, A. O. and Walker, J. C. G. (1977). J. Geophys. Res., 82, 4829.
Rusch, D. W., Torr, D. G., Hays, P. B. and Walker, J. C. G. (1977). J. Geophys. Res., 82, 719.

Spencer, N. W., Niemann, H. B. and Carignan, G. R. (1973). Radio Sci., 8, 284.

Torr, D. G. (1979). J. Geophys. Res., 84, 1939.

Torr, D. G. and Orsini, N. (1977). Planet. Space Sci., 25, 1171.

Torr, D. G. and Orsini, N. (1978). Geophys. Res. Lett., 5, 657.

Torr, D. G., Orsini, N., Torr, M. R., Hanson, W. B., Hoffman, J. H. and Walker, J. C. G. (1977). J. Geophys. Res., 82, 1631.

Torr, D. G. and Torr, M. R. (1979a). J. Atmos. Terr. Phys., 41, 797.

Torr, D. G. and Torr, M. R. (1979b). J. Geophys. Res., $\mathbf{8 5}, 783$.

Torr, M. R. and Torr, D. G. (1979c). Geophys. Res. Lett., 6, 775 .

Torr, M. R., Torr, D. G., Ong, R. A. and Hinteregger, H. E. (1979). Geophys. Res. Lett., 6, 771.

Torr, M. R., Torr, D. G. and Ong. R. A. (1980). J. Geophys. Res., in press. 